\title{
Značilnosti krajše proze slovenskih književnic ${ }^{1}$
}

\author{
SilviJa Borovnik \\ Univerza v Mariboru, Filozofska fakulteta, Koroška cesta 160, \\ SI-2000 Maribor, silvija.borovnik@um.si
}

\begin{abstract}
Članek se ukvarja z značilnostmi krajše proze slovenskih pisateljic vse od njenih začetkov, to je s preloma iz 19. v 20. stol., pa do sodobnosti. Izbor avtoric in literarnih besedil opozarja na tematske in jezikovno-slogovne novosti ter posebnosti v njihovi literaturi, pa tudi na bele lise pri raziskovanju in poznavanju le-te.
\end{abstract}

This article discusses the characteristics of Slovenian female writers' short prose from its beginnings (at the turn of the 19th to 20th century) to the present. The selection of authors and literary texts alerts us to the thematic and linguistic novelties and peculiarities of their literature. The selection also exhibits lacunæ in research and knowledge of the aforementioned literature.

Ključne besede: slovenske pisateljice, krajša proza, tematske in jezikovno-slogovne značilnosti

Key words: Slovenian female writters, short prose, thematic and linguistic-stylistic features

V letošnjem letu sem izdala knjigo z naslovom Kliči me po imenu (Ljubljana: Študentska založba, 2013), ki prinaša izbor iz krajše proze slovenskih avtoric 20. in 21. stoletja. Knjiga je nastajala ob zavesti, da Slovenci svoje literarne ustvarjalke, tako starejše kot sodobne, premalo poznamo in da njihova literarna dela niso dovolj uzaveščena. Le malo bolj natančen pregled književnosti, ki so jo pri nas ustvarile ženske, pa pokaže, da je bila ta vselej zelo zanimiva, raznolika in kakovostna, čeprav pogosto odrinjena na rob literarnozgodovinske pozornosti. Moj izbor je bil zastavljen tako, da opozarja na bele lise, obenem ${ }^{1}$ Članek je nastal v okviru raziskovanja programske skupine P6-0156 na FF Univerze v
Mariboru. 
pa tudi z mislijo na tematske in jezikovno-slogovne novosti in posebnosti $\mathrm{v}$ literaturi izbranih slovenskih prozaistk.

Že v literaturi prvih slovenskih literarnih ustvarjalk, na prelomu iz 19. v 20. stoletje, se je pojavila ženska kot upornica zoper tradicionalne, patriarhalne vloge, in že prve pomembnejše slovenske pisateljice so načenjale številne tabuizirane teme iz slovenskega družbenega in družinskega življenja. Ta tradicija je ostala živa vse do danes. Tako besedila avtoric iz prve polovice 20. stoletja močno odslikavajo podrejeni položaj ženske v patriarhalni družbi. Prav dobro je tudi razvidno, kako so si morale ženske v primerjavi z moškimi svojo pot do izobrazbe in posledično do umetniške ustvarjalnosti trdo izboriti. Najizrazitejše pisateljice tega obdobja - Zofka Kveder, Alma Karlin, Milena Mohorič, Marija Kmet, Milica Ostrovška, Ilka Vašte - so bile tudi svojevrstne borke za ženske pravice in upornice zoper stereotipne vloge žensk v družbi. Zaradi tega so bile pogosto zasmehovane, omalovaževane, nekatere pa tudi politično izobčene in kaznovane. O tem pričajo njihove biografije, na katere v okviru omenjene knjige še posebej opozarjam. Tudi literarna zgodovina jih je pogosto postavljala na stranski tir. Označene so bile kot »spremni pojavi« ali kot »sopotnice« pomembnih literarnih smeri in pisateljskih kolegov.

Čas pred drugo svetovno vojno, pa tudi obdobje neposredno po njej, je v slovenskem prostoru prinesel mnogo zanimivih literarnih ustvarjalk, ki pa seveda niso pisale le kratke proze, temveč tudi poezijo, romane in dramska dela. Družbeni odnos do njih se je zaradi njihove aktivne udeležbe v javnem življenju že med vojno samo, še bolj pa v novi državi Jugoslaviji, vsaj na deklarativni ravni polagoma spreminjal, vsekakor pa je postala pot do njihovega univerzitetnega študija bolj dostopna in manj izpostavljena predsodkom, kakršni so bili značilni za prvo polovico 20. stoletja. Toda spremenjeni odnos do vloge ženske v literarnem življenju je bil posledica dela pisateljic samih, njihove angažiranosti in kakovostnih literarnih objav, tako da niso več ostajale neopažene. V skupino pisateljic, ki so pomagale premikati mejnike v povojni družbeni zavesti, sodijo zlasti Mira Mihelič, Branka Jurca, Gitica Jakopin in še nekatere. Če sledimo podatkom iz njihovih biografij, opazimo, da gre za vedno bolj izobražene avtorice, dokler na koncu dvajsetega stoletja niso več redke niti take z magisteriji in doktorati. To pa je slika, o kakršni so lahko avtorice z začetka 20. stoletja, na primer tiste, ki so pisale za Slovenko, prvi slovenski ženski časopis, ki je na prelomu iz 19. v 20. stol. začel izhajali v Trstu kot priloga Edinosti, samo sanjale. Prav tako pa tudi njihova krajša proza ni več le tematizacija ženskih problemov, temveč ponuja v premislek najrazličnejše konflikte in stanja, tudi družbeno-politična. Jezikovno-slogovno najdemo v tej krajši prozi vse od psihološkega realizma, modernizma, postmodernizma in t. i. novega realizma ob koncu stoletja do najnovejših slogov in možnosti, ki jim literarna zgodovina še ni našla enotnega imena. Ob tem lahko opozorimo na paleto žanrskih značilnosti v najnovejših literarnih besedilih - nastale so zgodovinske, ljubezenske, erotične, kriminalne, potopisne in druge zgodbe. In ponovno, kot na začetku stoletja, se pojavljajo avtorice z dvojno jezikovno, včasih pa tudi nacionalno identiteto - Brina Svit, Maruša Krese, Erica Johnson 
Debeljak in Maja Haderlap (sicer kot avtorica romana). Te identitete izražajo zanimive večkulturne in medkulturne prostore, v katerih pisateljice živijo in ustvarjajo.

V razvoju književnosti, ki so jo v zgodovini pričenjale oblikovati Slovenke, pripada pisateljici ZOFKI KVEDER (1878-1926) posebno mesto. Novejša literarnozgodovinska spoznanja poudarjajo, da je bila v času, ko je bilo literarno snovanje pretežno moška dejavnost, zelo drzna, samosvoja in inovativna osebnost. Ena najbolj natančnih raziskovalk njenega literarnega opusa in urednica njenega Zbranega dela, Katja Mihurko Poniž, je v svoji monografiji o njej zapisala, da je bila Zofka Kveder »ženska, ki je v svojem življenju in delu poskušala uresničevati drugačne podobe ženskosti, kot jih je bila pripravljena sprejeti družba na koncu 19. in v začetku 20. stoletja« in da je v slovensko literaturo »vnesla reprezentacije ženskosti, ki jih do njenih del ni bilo, in v našo kulturno zavest podobo ustvarjalke, ki ni pisala le za razvedrilo, ampak tudi za preživetje« (Mihurko Poniž 2003: 9). Rojena je bila v Ljubljani, živela v provincialnem Loškem potoku, trdno odločena, da si v svetu, v katerem ni bilo prostora za ženske, najde in uresniči svojo poklicno ambicijo, pa je zapustila dom, se zaposlila ter si brez podpore staršev poiskala pot do izobrazbe na univerzah v Bernu in Pragi, kjer je pričela objavljati kratko prozo in v samozaložbi izdala zbirko črtic Misterij žene (1900). Nadaljevala je tako, da si je s svojimi literarnimi objavami pridobila ugled v slovenskem, češkem, po preselitvi v Zagreb pa tudi $\mathrm{v}$ hrvaškem slovstvenem svetu. Kvedrova je bila nadarjena in bistra osebnost, ki se je boleče zavedala neenakopravnega položaja žensk svojega časa, njihove fizične in psihične podrejenosti, pa tudi trpljenja zaradi neuresničenih intelektualnih želja. Njeno pisanje pomeni en sam upor zoper patriarhalne vzorce življenja. Ker je načenjala tudi tabuizirane podobe slovenskega življenja, tako družbenega kot zasebnega, je naletela na odpor predvsem v konzervativnih krogih. Ti so pisateljico izničevali in jo poniževali. To je bil namreč čas, ko so ženske želje vsaj po minimalni svobodi in enakopravnosti označevali kot nemoralne, željo po njihovih političnih pravicah pa kot pomožačenje (Jogan 2001: 22-39). Gibanja za osvoboditev žensk so bila označena kot nekaj bolnega in škodljivega. Kvedrova pa je razkrivala tudi podobe pretirane verske gorečnosti, nasilja v družini, alkoholizma in spolnih zlorab. Slogovno kaže njena proza na elemente moderne, naturalistične poteze pa so prepoznavne tako v nekaterih črticah kakor tudi v romanih Njeno življenje (1914) in Hanka (1918). Kvedrova je videla izhod iz patriarhalnih vzorcev svoje generacije v izobraževanju žensk, na osnovi katerega si bodo lahko priborile tudi ekonomsko samostojnost. Pisala je v treh jezikih, to je slovensko, nemško in hrvaško, saj je bil prostor, v katerem je živela, večkulturen. Njene objave v tedanjih časopisih (Prager Presse, Agramer Tagblatt, Dokumente der Frauen, Die Zeit, Universum, Jugoslavenska žena) pa dokazujejo, da je bila široka in razgledana osebnost.

Pravo posebnost med pišočimi avtoricami iz prve polovice dvajsetega stoletja predstavlja prav gotovo Alma Karlin (1889-1950), rojena v slovenski družini v Celju, ki je bila hči avstro-ogrskega častnika in matere, ki je bila po poklicu učiteljica. V družini so znali slovensko, a jezik njenega vsakdanjega 
komuniciranja in poznejšega izobraževanja je bila nemščina. Alma Karlin je bila poliglotka, svoja literarna dela in številne potopise, ki so že za časa njenega življenja izhajali po Evropi in drugje po svetu, je napisala v nemščini. Njen opus obsega štiriindvajset knjig, več kot štirideset proznih del in pesmi je ostalo $\mathrm{v}$ rokopisu in je delno še vedno neraziskanih. Že od otroštva si je želela postati raziskovalka tujih kultur in pisateljica in zaradi tega se je po šoli v Gradcu podala $\mathrm{v}$ London, kjer je na tamkajšnji univerzi diplomirala iz osmih jezikov. Spomladi 1919 se je nato odpravila na dolgo potovanje okrog sveta, ki je trajalo kar osem let, s teh svojih popotovanj, ki so jo zanesla tudi v predele, kamor še ni stopila ženska noga, pa je nenehno pisala in svoja besedila objavljala v najbolj branih časopisih svojega časa. Na potovanjih je bila sama, s pisalnim strojem Erika in brez spremstva, njeno delo pa je bilo tudi antropološko, etnološko in etnografsko. Prepotovala je Peru, Panamo in države Srednje Amerike, pot jo je zanesla na Havaje in na Japonsko ter Kitajsko, pa tudi v Korejo, Avstralijo in Novo Zelandijo, v Indonezijo, Tajsko in Burmo. Njena zadnja postaja je bila Indija, od koder se je 1.1928 vrnila v domače Celje k bolni materi. Alma Karlin je pisala potopise, romane, novele, pesmi in dramska dela ter objavila številne članke. Zagotovo je bila najbolj plodovita in cenjena pisateljica svojega časa, merjeno tudi v mednarodnem, ne le slovenskem merilu. Kot antifašistko jo je med drugo svetovno vojno preganjal gestapo, zato je pobegnila v partizane. Tam pa so jo kot pripadnico nemške nacionalne skupnosti sprva hoteli likvidirati, a jo je rešila partizanska prijateljica. Po vojni je živela skromno in odmaknjeno življenje v bližini Celja, skupaj z nemško slikarko Teo Gammelin. Po vojni, $\mathrm{v}$ času socializma, je zanimanje zanjo iz ideoloških razlogov, bila je namreč nasprotnica komunizma, usahnilo, pisala pa je poleg tega še v nemščini, ki je bila nezaželen jezik, jezik okupatorjev. V osemdesetih letih dvajsetega stoletja pa je njena literatura $\mathrm{z}$ novimi prevodi v slovenščino ponovno oživela. Novejši raziskovalci vidijo $\mathrm{v}$ njeni osebnosti izstopajočo intelektualko in pisateljico, zagotovo pa eno najbolj samosvojih in nenavadnih osebnosti, kar smo jih na Slovenskem kdajkoli poznali. V času, ko so pričeli izhajati potopisi Alme Karlin, ženske še niso potovale veliko in zlasti ne same po svetu. Tiste ženske, ki so potovale, pa so izvirale navadno iz bogatejših slojev. Potopisi Alme Karlin ne pričajo le o njenem velikem pisateljskem talentu, temveč tudi o njeni neizmerni želji po raziskovalnem delu, saj je svojim bralcem predstavljala posebnosti tujih, takrat še popolnoma eksotičnih kultur.

V prvi polovici dvajsetega stoletja je nadalje pisalo še veliko žensk, o čemer pričajo njihove objave $\mathrm{v}$ takratnih slovenskih časopisih in revijah, toda njihova literatura je ostajala manj opažena, polagoma pa je tudi povsem utonila v pozabo, dokler je šele na koncu dvajsetega stoletja in na začetku novega, zdaj ne odkrivajo in javnosti predstavljajo posamezni literarni zgodovinarji in zgodovinarke. Med tistimi, o katerih se do nedavnega niti $\mathrm{v}$ znanstvenih krogih ni vedelo veliko ali skoraj nič, je tudi MiLena MoHorič (1905-1972). Pisateljica je bila mojstrica kratke zgodbe v tridesetih letih. Diplomirala je iz germanistike, vse življenje pa se je ukvarjala tudi z ženskim vprašanjem, zato so osrednje osebe $\mathrm{v}$ njeni prozi ženske, navadno meščanke, njene novele in 
črtice pa ponujajo najboljšo sliko iz življenja slovenskega meščanstva iz obdobja med obema svetovnima vojnama. Po prepričanju je bila socialistka, od leta 1942 tudi komunistka in partizanka, kljub temu pa je skupaj z možem in sinom po vojni postala žrtev revolucije. Njen mož in sin sta bila namreč kot sovražnika države deportirana na Goli otok, od koder se mož ni več vrnil živ, sin pa je bil tam zaprt kar osem let. Tudi ona je bila obtožena informbirojevstva. Vse to jo je psihično zlomilo, njena proza pa je bila povsem odrinjena v pozabo. Zanimanje zanjo je oživelo šele v zadnjem času, ko je Lado Kralj skupaj s Petrom Scherberjem in Alenko Puhar objavil njene Zgodbe iz tridesetih let. V času, v katerem je objavljala, je bila deležna podcenjevalnih teorij, da ženska ni sposobna delati na intelektualnih področjih (v skladu s tedaj razširjeno teorijo Ota Weiningerja), ona pa je objavljala $\mathrm{v}$ številnih tedanjih časopisih in revijah (Ženski svet, Jutro, Mladina, Ljubljanski zvon, Modra ptica, Naša žena). Tematizirala je številne ženske usode in kazala na to, kako se morajo ženske moškemu svetu zgolj prilagajati. Ženske z lastnimi poklici ali s končanim univerzitetnim študijem pa so bile na Slovenskem redke in črtice Milene Mohorič so opozarjale na tak svet nemožnosti. Po svojem idejnem svetu predstavlja proza Milene Mohorič nadaljevanje tistega, za kar se je v svojih besedilih zavzemala Zofka Kveder.

Podobno so zunaj literarnozgodovinske pozornosti zelo dolgo ostajale lirske in celo ekspresionistično zaznamovane črtice MARIJE KMET (1881-1974), pisateljice, ki je bila $\mathrm{v}$ resnici pomembna ustvarjalka $\mathrm{v}$ obdobju med obema vojnama. Po poklicu je bila učiteljica, glavnino svojih črtic pa je objavila v tridesetih letih (v Slovenskem narodu, Ljubljanskem zvonu in Ženskem svetu). V njej je tematizirala avtobiografske izkušnje, položaj učiteljic, dvojno moralo družbe, motive iz prve svetovne vojne, posvečala pa se je tudi položaju slovenske ženske; nekatere črtice prikazujejo tudi elemente nasilja nad ženskami in njihovo zlorabo. Literarni zgodovinarji zdaj opozarjajo, da so nekatere njene črtice bolj pesmi v prozi in da kažejo poleg znamenj simbolizma in dekadence tudi jasne poteze ekspresionizma. Marija Kmet je objavila dve zbirki kratke proze, in sicer Bilke (1920) in Večerna pisma (1926). Prav Večerna pisma je sočasna literarna kritika neprijazno sprejela, pisatelj Ivan Pregelj pa je ob njihovem izidu zagrešil svojo »znamenito《 izjavo: »Nisem prijatelj žensk, ki pišejo, ne naših ne tujih. Celo tistih ne, ki moško pišejo« (v Domu in svetu, 1927). Oboje omenjam, da bi lažje razumeli atmosfero, ki je pisateljevanje še dolgo v dvajseto stoletje razumela kot moško dejavnost. Ženske, ki so posegale na to področje, so bile nezaželene in posledično tudi nerazumljene.

Podoben primer pisateljice iz obdobja med obema vojnama je MiLICA OstrovšKa (1907-1997), ki je v Ljubljani študirala primerjalno književnost, jezikoslovje in nemški jezik ter bila v letih 1928/29 kot štipendistka francoske vlade celo študentka na pariški Sorboni. Pod vplivom Srečka Kosovela je postala levičarka, na začetku vojne izgnana v Srbijo, po vojni pa kot sovražnica države deportirana na Goli otok, kjer je bila zaprta tri leta in nato brezposelna. Po vojni je živela v Mariboru, a literarnih del v tem obdobju ni več pisala. Objavljala je v Ženskem svetu, njene črtice pa so primer besedil, ki so tematizirala žensko 
usodo v obdobju gospodarske krize tik pred drugo svetovno vojno. Besedila so napisana $\mathrm{v}$ realističnem slogu z zanimivimi psihološkimi prvinami, ženske pa je Ostrovška prikazovala tudi v perspektivi razpetosti med tradicionalnimi in emancipiranimi vlogami.

Med plodovite pisateljice, ki so začenjale pisati že pred drugo svetovno vojno, sodi še IlKa VAšTe (1891-1967), ki se je potem, ko je mlada ovdovela in ko je bil Trst po razpadu Avstro-Ogrske priključen Italiji, preselila v Ljubljano. Postala je ena najplodovitejših slovenskih romanopisk in cenjena avtorica zgodovinskega romana. Izdala je kar šestnajst knjig, kot pisateljica pa je bila pri literarnih kritikih in zgodovinarjih pogosto podcenjevana, vendar pri bralcih vseskozi priljubljena. Slogovno se je gibala v mejah realizma, njeno slovstvo pa je imelo pomembno narodno-osveščevalno in kulturno-prebujevalno vlogo. Tematizirala je slovensko zgodovino od naselitve pa do reformacije in Ilirskih provinc. Njeno najbolj znano delo je Roman o Prešernu (1937), ki je doživelo več izdaj. Kot ena redkih slovenskih pisateljic pa je zapustila tudi avtobiografijo, ki je pravzaprav zbirka krajših proznih zapisov z naslovom Podobe iz mojega življenja (1964). Zbrane črtice so primeri zelo kultivirano in tekoče napisane ter na poseben način duhovite kratke proze.

Tik po drugi svetovni vojni se v slovenskem prostoru pojavi kar nekaj nadarjenih pisateljic, ki pa so pričenjale pisati tik pred vojno, a je vojna njihovo ustvarjalno pot na silo prekinila. To so denimo Ljuba Prenner, Branka Jurca, Mira Mihelič in Mimi Malenšek. Branka JurCa (1914-1999) je bila na primer med vojno aktivna članica OF in zato zaprta v taboriščih Gonars in Ravensbruck, po vojni pa se je posvečala predvsem mladinski in otroški književnosti. Toda pisala je tudi avtorsko prozo za odrasle, med katero naj omenimo zbirko črtic Stekleni grad (1958), ki prinaša prečiščene utripe iz življenja predvojnega in povojnega človeka, obenem pa prikazuje tudi tegobe žensk v obliki subtilnih psiholoških zapisov. Med omenjenimi je najuspešnejšo povojno literarno pot opravila MiRA MineLIČ (1912-1985), namreč kot pisateljica in prevajalka ter doslej edina ženska, ki je predsedovala Društvu slovenskih pisateljev in slovenskemu centru PEN. Prav na pragu vojne je objavila svoja prvenca, romana Obraz v zrcalu (1941) in Tiha voda (1942), ki sta izhajala iz bogate tradicije evropskega kronikalnega romana. Mira Mihelič je bila svetovljanska osebnost, ki je slovenski prostor v času socializma, ko je bil le-ta politično še dokaj zaprt, odpirala svetu in v Slovenijo pričenjala vabiti ugledno mednarodno pisateljsko družbo, najprej v Piran, od tam pa na vsakoletna srečanja PEN na Bledu, ki se odvijajo še danes. Bila je romanopiska, novelistka, dramatičarka in prevajalka številnih del iz svetovne literature v slovenščino. Njeno avtorsko prozo pa je že od vsega začetka zaznamovala avtobiografskost, ki je tematizirala propad slovenskega meščanstva, pri čemer je Miheličeva osrednjo pozornost namenjala ženskim likom. Le-ti niso bili odsev njene feministične zavzetosti, temveč razčlenjevalne vneme v okvirih psihološkega realizma. V nasprotju z nekaterimi drugimi je bila Mira Mihelič že za časa svojega življenja znana in priznana literarna ustvarjalka. Njena najbolj kvalitetna dela, npr. romana April in Hiša večera (oba 1959), pa so bila tudi nagrajena. Bralcem je zapustila tudi 
nadvse zanimivo napisano avtobiografijo Ure mojih dni (1985) ter številna druga dela.

Med povojnimi avtoricami starejše generacije naj omenim še GITICO JAKOPIN (1928-1996) in ZoRo TAVČAR (1928). Prva je izbor svoje kratke proze izdala šele leta 1995 z naslovom Duša, kaj želiš, druga pa svoj izbor pod naslovom Ob kresu življenja leta 1989.

Med avtorice, ki so s svojimi proznimi besedili vzbujale pozornost v sedemdesetih in osemdesetih letih dvajsetega stoletja, sodi Ivanka Hergold (1943), ki kot samostojna književnica živi in dela v Trstu. Piše prozo, poezijo, esejistiko, dramatiko in prevaja iz italijanščine. V samostojnih knjižnih izdajah je izšlo več zbirk njenih novel in črtic, npr. Pasja radost ali karkoli (1971), Beli hrib (1973), Dido (1974), Vse imaš od mene (1974) in Pojoči oreh (1983). Njeno delo dokazuje, da je zanimiva krajša proza izpod ženskega peresa nastajala že pred letom 1980, ko se je na Slovenskem v okviru postmodernističnih oblikovnih in slogovnih postopkov razmahnilo kratkozgodbarstvo. In čeprav o postmodernizmu pri Hergoldovi še ne moremo govoriti, se nekatere njegove značilnosti že napovedujejo. Njene fabule prinašajo pripovedi s socialnega roba, njeno priljubljeno stilno sredstvo pa je groteska.

Osemdeseta in devetdeseta leta 20. stoletja so obdobje razvitega slovenskega postmodernizma, $v$ tem času pa se na literarnem prizorišču pojavlja generacija pisateljic, rojena $\mathrm{v}$ šestdesetih letih, ki je sicer še doraščala v socializmu in je delno še obremenjena $z$ nekaterimi njegovimi travmami, obenem pa je iz proze prav dobro razvidno, da jo piše generacija avtoric, ki je lahko že brez posebnih težav študirala na domačih in tujih univerzah, se tam razgledala, v slovenski literarni prostor pa vnesla posebno vrsto svežine. Namesto pesimistične slovenskosti prinaša ta proza širino evropskih in svetovnim literarnih tokov, do nacionalnopolitičnih tem, ki znotraj socialistične Jugoslavije ostajajo še vedno pereče, pa goji ironičen in satiričen odnos. Namesto političnih tem je v ospredju tema ženske in ženskega, iskanja lastne identitete in mesta v svetu, tudi v Sloveniji, ki je sicer polna duhovnih in političnih pretresov. Pisateljice prikazujejo različne oblike sodobne ženske odvisnosti v razmerju do družine, družbenega statusa in biološke narave. Nekatere opozarjajo tudi na omejevanje svobode žensk, tako osebne kot politične, čeprav bi jim na deklarativni ravni država rada dopovedovala, da so svobodne in enakopravne.

V tej skupini pisateljic izstopa delo LeLE NJATIN (1963), roman Nestrpnost (1988), ki pa je napisan v izrazito fragmentarni obliki kot zbirka matričnih fabul, polnih prizorov nasilja, mučenja, sadizma, mazohizma. Razumemo jih kot avtoričin protest zoper vsemilitaristično navzočnost v svetu - tedaj še Jugoslavije - ki brez svojih obveznih parad nasilja ni znal živeti. Ženska v takem svetu predstavlja le objekt, na katerem oblast demonstrira svojo moč. Pripovedovalka nakazuje zrcalno sliko življenja, ki ga nadzoruje močan vojaški aparat. Tematizacija ženskega je v prozi Lele Njatin povezana z ostro družbeno kritiko. Med tiste, ki vztrajno vrtajo v fenomen ženskosti, sodi tudi delo MıLoJKE ŽIŽMOND KofOL (1948), npr. novelistični zbirki Polovica ženske (1990) in Levitve (1991). Od takrat pa do danes se je takih avtoric pojavilo že bistveno 
več, njihova dela pa so pričenjala izhajati okrog leta 1990 (poleg kratke proze še romani Berte Bojetu Boeta, Marjete Novak Kajzer in Katarine Marinčič, pred tem pa že poezija Svetlane Makarovič).

Poigravanje z različnimi žanri, zlasti z žanrom kriminalke, strašljivke in grozljive zgodbe, opredeljuje prve literarne objave MAJE NovaK (1960) in SILVIJE BorovNiK (1960). Majo Novak je po objavi njenih romanov z naslovoma Izza kongresa ali umor v teritorialnih vodah (1993) in Cimre (1995) slovenska literarna publicistika pričela imenovati prvo damo slovenske kriminalke. Posebnost njenih kriminalk se je izkazovala $\mathrm{v}$ dejstvu, da je pisateljica ta žanr duhovito parodirala in ga večslojno zakodirala, $v$ njem pa spretno in z velikim smislom za ironijo preigravala različne postmodernistične možnosti literarnega izraza. Za zbirko kratke proze Zverjad (1996) je prejela nagrado Prešernovega sklada. Gre za mojstrske prozne miniaturke, ki opozarjajo na brutalnost tako imenovanega civiliziranega sveta, se posmehujejo političnim diktaturam in se razvijajo v prave groteske. Zgodbe so tudi polne duhovitih besednih iger, ki vodijo bralca skozi različne svetove medbesedilnosti. Podobne značilnosti lahko opažamo v prozni zbirki Strašljivke (1990) Silvije Borovnik, ki prav tako eksperimentirajo z igrivimi možnostmi postmodernizma, med katerimi je kot priljubljena oblika zaživela prav kratka zgodba kot zgodba z nenavadnim zapletom in odprtim koncem. V delni okvir omenjenega priljubljenega sloga sodi tudi krajša proza LucıJe StePANČIČ (1969), zbirka Mrtvaki in šlagerji (1997), ki je polna citatnih elementov in humornih medbesedilnih prebliskov. Večkrat gre za fragmentarno prozo, ki se posmehuje vajenemu, vsakdanjemu, utirjenemu svetu, zlasti značilnim slovenskim navadam in običajem.

Posebno obliko medkulturnosti lahko opazujemo v prozi BRINE SvIT (1954), Ljubljančanke, ki živi v Parizu in v zadnjem času piše literaturo ne le v slovenščini, temveč tudi $v$ francoščini. Danes je to namreč slovensko-francoska pisateljica, tudi prejemnica uglednih francoskih literarnih nagrad. Čeprav objavlja v glavnem romane in esejistiko, pa je bil njen prozni prvenec April (1984) napisan v fragmentarni obliki, kar je ostalo značilno za njeno prozo vse do danes. Tudi krajši roman Moreno (2003) bi lahko označili kot zbirko kratkoproznih fragmentarnih zapisov, zaznamovanih s temo iskanja ženske, pa tudi jezikovne, nacionalne in nove pisateljske identitete, posebno pa ženskega obraza in njene ljubezenske sreče. Vedno znova pa lahko pri njej opazujemo preigravanje staroljudskega motiva lepe Vide in njenega silovitega hrepenenja. Literatura Brine Svit pripoveduje o tujstvu, ki je lahko prostovoljno izgnanstvo, obenem pa razkriva še podobe tujstva v sodobni Evropi, ki so nastale iz trdih preživetvenih razlogov.

Iz perspektive tujine nagovarjata slovenski prostor še dve pisateljici. SonJA Porle (1960) je etnologinja, publicistka in pisateljica, ki živi v Oxfordu. 1983 je prvič obiskala Afriko in odtlej je vsa njena dejavnost ljubeče posvečena raziskovanju afriške kulture. Kot književnica se je odločila za obliko potopisnega romana, katerega začetnica je bila pri nas Alma Karlin. Tudi velika vnema Sonje Porle, da bi neznane kulture približala bralcem, spominjajo na njeno izjemno predhodnico. Druga avtorica pa je MARUŠA KRESE (1947-2013), ki se je dolgo 
izmikala slovenski literarnozgodovinski pozornosti, najbrž zato, ker je veliko potovala po svetu in živela $\mathrm{v}$ Berlinu, kjer je svoje publicistične in literarne prispevke objavljala tako $\mathrm{v}$ slovenščini kot $\mathrm{v}$ nemščini. S svojimi teksti se je posebno občutljivo odzivala na usode žensk in otrok v svetu, ki so ga zaznamovale vojne in posledično humanitarne katastrofe, o čemer je napisala številne eseje in nastopala na mednarodnih konferencah (Frauen uber Nationalismus und Krieg/Ženske o nacionalizmu in vojni, 1993). Kresetova pa sodi tudi med prepoznavne avtorice kratke proze. Leta 2006 je izšla njena zbirka Vsi moji božiči/Alle meine Weihnachten, za katero se skriva avtoričina tragična, a tudi samoironična avtobiografija, napisana $\mathrm{v}$ dosledni tradiciji minimalizma. Božič v njenih zgodbah je podoba osamljenosti, večkrat revščine, iskanja identitete, neizpolnjenih hrepenenj, pa tudi nenehnih potovanj, ki izražajo beg pred samo seboj.

Če bi sledili biografskim podatkom sodobnih slovenskih pisateljic, bi nedvomno opazili, da imamo opraviti z vedno bolj izobraženimi avtoricami, s takimi, ki z opravljenimi magisteriji in doktorati predavajo tako na domačih kot tujih univerzah ter ne delujejo le literarno, temveč še na številnih drugih področjih. Kot razgledane in občutljive osebnosti načenjajo mnoge, tudi tabuizirane teme iz slovenskega vsakdanjega življenja. Taki sta npr. BoJana Kunst (1969), doktorica filozofije, ki v svoji zbirki kratke proze Višnje v čokoladi (1997) prikazuje mnoge drzne erotične prizore, pa tudi SuZANa TRATNiK (1963), sociologinja in antropologinja, ki tematizira probleme drugačne, istospolne identitete, ter Vesna v. Godina (1957), socialna in kulturna antropologinja, znanstvenica in publicistka, ki je na literarno polje stopila s svojo dnevniško-potopisno prozo Havaji na papirju, s katero razodeva pronicljive, analitične poglede na slovensko družbeno stvarnost. Ambiciozno literarno pisavo razodeva tudi krajša proza doktorice literarnih ved BARbare Simoniti (1963) z naslovom Razdalje (1998), avtorica pa je tudi pesnica in prevajalka.

Na koncu 20. in na začetku 21. stoletja se zdi, da se je slovenski literarni postmodernizem že izpel, tako da tudi literarna pisava novejših slovenskih pisateljic prinaša nove oblike izraza. Literarna veda jih imenuje zelo različno, večkrat pa beremo o t. i. novem realizmu. Najbrž je potrebno še več časa, da se bodo novejši literarni slogi in smeri izkristalizirali ter da bomo med njimi ločili najbolj pogoste in izrazite. Po letu 2000 izide mnogo vznemirljivih kratkoproznih zbirk, npr. avtoric kot so LiLI PotPaRA (1965) Zgodbe na dušek (2004) pa Polone Glavan (1974) Gverilci (2004), nadalje še Veronike Simoniti (1967) Zasukane štorije (2005), URŠKE STERLE (1979) Vrsta za kosilo (2006) in CvetKe Bevc (1960) Zgodbe iz somraka (2007). Med njimi izstopa literarno delo Američanke Erice Johnson DebelJak (1961), ki živi v Ljubljani, piše v angleščini in jo prevajajo v slovenščino. Pisateljica namreč odraža pojav, pogost v globaliziranem svetu, ko nekateri avtorji/-ice dobivajo zaradi življenja in literarnega ustvarjanja v novem, zanje tujem geografskem in jezikovnem okolju, novo, tako rekoč dvojno literarno identiteto. Johnson Debeljakova je namreč tudi slovenska pisateljica. Njena proza je vznemirljivo kritična, izraža posebne poglede kritične intelektualke, pa tudi bolečo razpetost med tujim in domačim, 
med svetovnim in slovensko nacionalnim. Njena emigrantska izkušnja drugačnosti v novem okolju je razvidna iz vse njene avtobiografske proze, pa tudi iz zbirke krajše proze z naslovom Tako si moj (2007), ki potrjuje avtoričin dar za oblikovanje zanimive zgodbe. Protagonistke v njej so ženske, ki so kljub ranljivosti in številnim dvomom močne, nekonvencionalne in izobražene.

Najnovejša krajša proza slovenskih avtoric je izrazito večplastna in komunikativna, pa tudi nepredvidljiva in šokantna. Pisateljice preigravajo elemente najrazličnejših popularnih žanrov, vse od sentimentalnih do grozljivih, pri čemer jim dobro služijo tako popikone kot elementi klasične književnosti, fantastičnost, pa tudi duhovite medbesedilne povezave. Pri takih prijemih prepoznavamo dediščino slovenske postmodernistične kratke zgodbe. Pisateljice ironizirajo slovenske stereotipe in nacionalno mitologijo, predvsem pa robove človekovih, zlasti ženskih osebnih izkušenj v sodobnem svetu. Izražajo protest zoper podrejanje družbenim klišejem in normam, zavzemajo se za samostojno in samosvoje življenje. Ukvarjajo se z vprašanjem, kaj se skriva za gladko, na videz urejeno površino človeških vsakdanjih življenj, in dokazujejo, da nobena oblika bivanja ni povsem enostavna, enoznačna in premočrtna. V tak kontekst sodi krajša proza VeSne Lemaić (1981) v Popularnih zgodbah (2008), MoJCE Kumerdej (1964) v zbirki Temna snov (2011) in Mirane Likar BAJžElu (1961) v Sobotnih zgodbah (2009). Videti je, da se z lastno temo položaja slovenske pisateljice le-te ne obremenjujejo, po čemer sicer ne moremo sklepati, da je ta idealen in brez bremen. O kvaliteti njihovega literarnega dela pa pričajo predvsem dela sama in žal prepogosto tudi prej tuje kakor domače literarne nagrade (kot v primeru Maje Haderlap za roman Angel pozabe, 2011, v Avstriji in Nemčiji, ali v primeru Brine Svit v Franciji). V Sloveniji pridejo kvečjemu do nagrade Prešernovega sklada, nikoli praviloma do Prešernove same, razen enkrat, ko jo je prejela Mira Mihelič, in enkrat, ko jo je odklonila Svetlana Makarovič, in preredko do kresnika, nagrade za najboljši slovenski roman, razen ko sta ga prejeli Berta Bojetu in Katarina Marinčič.

\section{VIRI IN LITERATURA}

Silvija BOROVNIK, 1995: Pišejo ženske drugače? Ljubljana: Mihelač.

- -, 2012: Književne študije: o vlogi ženske v slovenski književnosti, o sodobni prozi in o slovenski književnosti v Avstriji. Maribor: Mednarodna založba Oddelka za slovanske jezike in književnosti, Filozofska fakulteta (Zora, 85).

--, 2013: K izboru iz krajše proze slovenskih avtoric. Kliči me po imenu. Izbrala, uredila in spremno študijo napisala Silvija Borovnik. Ljubljana: Študentska založba. 372-435.

Andreja JEZERNIK, 2009: Alma Karlin. Ljubljana: Mladinska knjiga.

Maca JOGAN, 2001: Seksizem v vsakdanjem življenju. Ljubljana: Znanstvena knjižnica, Fakulteta za družbene vede. 
Lado KRALJ, 2010: »Danes so njene kratke zgodbe pozabljene«. Zgodbe iz tridesetih let. Ljubljana: Študentska založba. 134-169.

Lado KRALJ, Peter SCHERBER (ur.), 2010: Slovenske kratke zgodbe med koncem ene in začetkom druge vojne. Celje: Celjska Mohorjeva družba.

Katja MIHURKO PONIŽ, 2006: Kratka pripovedna proza Marije Kmet. Slovenska kratka pripovedna proza. Ur. Irena Novak Popov. Zbornik predavanj 23. Simpozija Obdobja. Ljubljana: Filozofska fakulteta.

- -, 2003: Drzno drugačna: Zofka Kveder in podobe ženskosti. Ljubljana: Delta.

Urška PERENIČ, 2007: Leposlovje Milice S. Ostrovške v reviji Ženski svet (1923-1941). Slavistična revija 3. 463-72.

Alenka ŠELIH (ur.), 2007: Pozabljena polovica. Portreti žensk 19. in 20. stoletja na Slovenskem. Ljubljana. DZS.

Tomo VIRK, 1998: Spremna beseda. Čas kratke zgodbe: antologija slovenske kratke zgodbe. Ur. Tomo Virk. Ljubljana: Študentska založba.

\section{CHARACTERISTICS OF SLOVENIAN FEMALE LITERARY WRITER'S SHORT PROSE}

The article gives an overview of the characteristics of Slovenian female writers' short prose since its beginnings until modernity. It indicates that even among the pioneers of Slovenian female writers there was a woman who rebelled against tradition and that many of other pioneers also discussed various taboo topics of Slovenian social and family life. This tradition persists to the present day. The article also provides an overview of the most distinctive female authors and their short prose of the entire 20th century. The first Slovenian female writers were frequently characterized as "fellow travelers" of the important literary directions and their male colleagues. Today the past and present female writers are recognized and share new literary historical findings and interpretations such as are found in this article. 